\title{
An audit of medicolegal conferencing
}

\author{
R G Pringle FRCS
}

J R Soc Med 2003;96:454-457

\section{SUMMARY}

In the English civil justice system, experts involved in a case are now commonly required to confer before the hearing and identify the areas of agreement and disagreement. A prospective study of 50 consecutive medicolegal conferences of experts was undertaken, with a view to defining their benefits, weaknesses and the optimum conference format. A record was kept of the dates of first instruction, court deadlines, and date, time and duration of conferences, together with related calls and correspondence. The manner of preparation of the statement was noted, the level of agreement/disagreement, any compromise, any later modifications of the draft, and the author's fees. Subsequently the instructing solicitors were asked to comment on the suitability of the joint statement and its contribution to settlement.

Medicolegal conferencing is time-consuming and expensive. It may be of limited value where there is little or no difference of opinion, either between experts in a single field or between experts in different fields. The instructing solicitors must ensure that the participants receive, in advance of the conference, copies of all relevant documents including medical reports and medical records. An agenda is helpful in ensuring that matters of importance are not overlooked. Conferences are more effective when held in person than when conducted by telephone. The joint statement is best dictated in the presence of all participants during or after the conference.

To ensure the most efficient and economical use of consultant time a formal combined audit of conferencing should be undertaken by the medical and legal professions.

\section{INTRODUCTION}

'My own experience is that, when experts come face to face, they tend to agree on more than they expected. Disagreements sometimes arise out of differences in expression, and meetings are useful in narrowing the issues in dispute - Butler-Sloss and Hall ${ }^{1}$

'These meetings are now where cases are won or lost. No amount of legal repair work can patch up the damage that can be caused to your case if your expert has been steam rollered into a concession by his/her opposite number'-Stevens ${ }^{2}$

When medicolegal conferences were introduced in April 1999 as a part of the Woolf reforms, experts became inundated with instructions. Conferences proved to be timeconsuming in terms of administration, both in their setting up and in the drafting and signing of the joint statements. Although the court commonly directed the experts to 'meet and confer', solicitors generally felt this could be ignored and that telephone conferences would suffice.

Deadlines laid down by the court not uncommonly seemed unrealistic. And was there any point in conferences

Burnell House, 82 Berwick Road, Shrewsbury SY1 2NF, UK

E-mail: lesley@burnellhouse.fsnet.co.uk where there appeared to be no areas of disagreement, or where the views were at polar opposites or between experts in different disciplines?

A postal survey of orthopaedic medicolegal consultants undertaken by the British Orthopaedic Association revealed that as a result of 'provocations' attributable to the Woolf reforms $12 \%$ of respondents had withdrawn their services. These provocations were largely attributable to problems with telephone conferencing. ${ }^{3}$ In an attempt to assess the difficulties associated with conferences and their value, I, an orthopaedic surgeon, conducted an audit of 50 consecutive conferences in which I participated. The instructions to confer were received between 30 November 1999 and 3 July 2001. The conferences took place between 7 August 2000 and 28 November 2001. Three months after the conference a questionnaire was sent to the instructing solicitors or insurance company. A second copy was sent after a further three months if no reply had been received.

\section{PERSONAL EXPERIENCE}

The 50 conferences dealt with forty-seven claimants: in 3 cases I was instructed to confer separately with experts in different disciplines (orthopaedic and pain, orthopaedic and spinal cord injury, and in one case an orthopaedic surgeon 
followed by a second, this time three-way conference with that surgeon and one with a relevant special interest). My own special interest is spinal and spinal cord injury.

There were 1 other three-way and 3 four-way conferences; of these, 3 were held in person, 1 by telephone.

Follow-up conferences proved necessary in 3 cases - in 2 because further investigations were recommended. In 3 cases there was alleged medical negligence.

\section{Deadlines}

On occasion a delay between the court order and the issuing of instructions makes the court deadline unrealistic. In this series the deadlines, laid down in 29 instances, ranged from 3 days (later changed to 14 weeks) to 16 weeks. In 12 cases the deadline was 4 weeks or less. Overall the deadlines were met in only 12, less than half. The deadlines were readily extended. Clearly they are better viewed as guidelines.

The average delay between receipt of instructions and the conferences was a little over 16 weeks, the figures skewed somewhat by 3 conferences where the delay was 52 weeks or more.

\section{Administration and outcomes}

Nearly 200 telephone calls (made and received) and over 200 letters - an average of 8 episodes per conferencewere required. Such administration is not helped by the fact that many consultants expect their secretaries to deal with requests for conference yet the secretaries are not empowered to make the definitive arrangement.

16 conferences (32\%) were held in person, the remainder by telephone. When the experts met, the joint statement was prepared and agreed at the conclusion of the meeting. In the case of telephone conferences, most statements were drafted by one expert after the discussion and submitted to the other for comment. In my experience, conferences in person lead to a more thorough consideration of the issues.

In 3 cases the duration of the conference was not recorded. The average duration of the remaining 47 was a little over 45 minutes, the briefest taking 10 minutes and the longest (multi-expert, tetraplegia with alleged negligence) 150 minutes.

Looking at the statements I found an area of significant disagreement in $25(50 \%)$. Where there was disagreement, it was rated as minor (1-2 on a scale of 5 ) in 17 , moderate in 2 and major in 6.

The first draft joint statement was agreed in 41.8 required modification, in 4 very substantial modification where one expert felt it did not fairly represent views expressed at the conference. In one of those cases the joint statement had been dictated during a four-way conference by one expert in the presence of and with the approval of the other three.

In 1 case the agreed joint statement was not accepted by the court as evidence. The experts, because of intervening summer holidays, had been unable to sign it before the trial. Both experts were then required to attend court, but the judge promptly released them.

In 8 cases it became apparent at the time of conference that one or other expert had not seen all the evidence. Unseen medical reports led to 2 conferences being aborted and 2 delayed, while in 2 the contents were presented by one party to the other during the conference. In 2 cases one expert had not seen surveillance evidence. This led to the postponement of one conference and a change of opinion in the other.

In 2 instances the opposing expert changed his or her opinion without explanation, and in one I modified my own views in the light of previously unseen surveillance evidence. In 1 case a conference between me and an expert in pain control seemed pointless in view of the different fields of expertise.

\section{Cost}

My average conference fee based on time spent was $£ 700$. This also was the average fee for the 7 conferences in person within a 10-mile radius but in 2 cases my fee was over $£ 2000$. These were conferences in person involving four experts. The average fee for telephone conferences was almost $£ 460$. The average total cost of the conferences in this series must be at least twice those figures.

\section{RESPONSES TO QUESTIONNAIRES}

Responses from solicitors or insurers were received to 37 (74\%) of the questionnaires.

Question 1: Was the joint statement helpful in contributing to the settlement?

Yes: 32

No: 1

In 3 cases this question was not answered because the case had not been settled, and in a fourth the statement was thought to have been 'likely to be helpful', again in a case not yet settled. 3 of those marked helpful were in cases which had not settled. In the case where the statement was deemed unhelpful, no reason was given.

Question 2: Did it help avoid a trial?

Yes: 21

No: 10

'It may': 1

Unknown or 'Not yet': 5 
Question 3: Were all aspects covered satisfactorily?

Yes: 34

No: 3.

The 'Nos': 1, again, was the case of the unsigned draft. In one the solicitors added, 'I think that this case illustrates how some consultants instructed on behalf of the claimants strive too hard to advance the claimant's case - and thereby become partisan. I do not consider that your "opposite number" in this case properly fulfilled his obligations to the court'.

Question 4: Was/would an agenda have been helpful?

Yes: 17. One comment: 'Agendas are helpful but need careful preparation. Consultants should be prepared to discuss matters with instructing solicitors before having joint meetings. In some cases we find consultants will change their minds without any explanation, which does not help the legal advisers'.

No: 16, including 'not in this particular case' (2) and 'probably' (1).

Question 5: If there was an agenda was it followed?

Yes: 9

In 26 cases none had been provided. In 18 of those, the answer to the earlier question had been No-i.e. an agenda would not have been helpful.

8 responders who had not provided agendas had answered Yes to the previous question, indicating that an agenda would have been helpful. This represents 20\% of the 41 conferences without an agenda. Box 1 records some free comments by solicitors.

Question 6: Were the conclusions surprising to you?

Yes: 3 (in 2 as a result of modification of opinion by the claimant's expert).

No: 33

Uncompleted: 1

Question 7: Did any of the claimants' or defendants' experts appear to shift ground?

Yes-Claimant: 8 (including one later resiling)

Yes-Defendant: 1

Yes - Both: 3 (including one 'helpfully' and one in which 'shift ground' was changed to 'modify their opinion'.)

No: 23 (including one where beside 'claimant' was written 'Not a lot').

Question 8: Do you think the presence of lawyers would be of benefit?

Yes: 3 (including the case of resilement).

No: 31. Comments included: 'Generally (there may be cases where it would be of benefit)'; '. . . sometimes where there has been very lengthy medical evidence with
Box 1 Comments from solicitors on conference agendas

'I agree that agendas are often difficult to prepare in practice, particularly where there are issues of causation. It is not uncommon for the experts to have to wrestle with two draft agendas where an agreed document has not been possible. In theory the agreement of an agenda should be a straightforward thing. I suspect it often proves difficult because solicitors (perhaps unconsciously) try to direct or confine the discussion to show their case in its best light and to avoid problem areas.'

'. . . quite often ... one side's agenda is a little different from the other's. Notwithstanding that comment, I do not think that imposing an agenda is a good idea . . . and by and large would prefer to trust to the good sense of those I send in to bat.'

'I do not believe that an agenda would be helpful but this is from my perspective. . . . I fully accept that experts involved in such joint discussions may well find an agenda as drawn up between themselves helpful. For the same reason I do not think that the presence of a lawyer at any joint discussions would be of assistance . . .'

‘. . Solicitors, for whatever reason, either do not prepare an agenda at all or the agenda is prepared late and is ill prepared. Frequently, I have seen reports which do not, in any event, follow the agenda. The question therefore arises as to whether the presence of lawyers would be of benefit at such joint meetings.'

several issues it might assist'; 'Doubt it — but their input is important'; 'No but depending on complexities of each case'.

Yes and No: 3. Comments included: 'Yes to ensure all points are addressed'; 'No-expense and inhibitions!'; '. . . depending on nature of injury and value of claim'; 'Possibly'.

Question 9: Do you think conferences in person are more productive than telephone conferences?

Yes: 18. Comments: 'Though impractical'; 'But the interest of proportionality might often override this factor and to save costs a telephone conference would be more appropriate. Experts should be guided by instructing solicitors'.

No: 11, including 'But depends on each case'.

Unanswered: 2

Question 10: Do you think the court orders such conferences too frequently/readily?

Yes: 4

Sometimes:

No: 30 including the following comments: 'Conferences between experts are usually ordered by the Courts now and tend to narrow the issues, if any, between the experts and 
avoid their attendances at trial'; 'It is always helpful for the experts to meet pre-trial to try and narrow the issues. The difficulty is where each expert has opposing views and neither party is prepared to concede anything - this just adds to the cost of the case- but at least it becomes apparent whether those experts have to give oral evidence at trial. Where there is little between the experts, written evidence and the joint statement will suffice'.

Unanswered: 2, including this comment: 'Conferences are invariably ordered where there is a medical issue. The purpose is to establish whether any given issue can be resolved without the need for a trial. I think they are now part of life.'

\section{DISCUSSION}

Pretrial conferences are time-consuming for the experts and expensive for the courts, but the great majority of solicitors considered them helpful. A few thought they were ordered too frequently. Clearly there is no point in conferring when there is no difference of opinion, while little is gained by conference between experts from widely differing disciplines. Perhaps, therefore, the courts could be more selective when ordering conferences.

When instructions are issued, experts must see all relevant medical and non-medical evidence. On occasion, this can lead to a change of opinion by one or both experts, averting the need for conference.

It is equally important that all experts should be informed fully of all issues on which they are to confer. The obvious way to do this is via an agreed agenda. This serves to focus the discussion and ensures that all issues are discussed. My own view is that agendas are desirable, and this was the majority view of respondents to the questionnaire.

However, there is no real agreement among the legal profession here. And who should prepare the agenda? In a survey by the Expert Witness Institute $436 \%$ of respondents said the agenda had been prepared by solicitors and 32\% by the experts. $28 \%$ claimed to have their discussion without any agenda.

Another question is whether or not the presence of a solicitor at conference is desirable, helpful, or indeed legal. According to Stevens, ${ }^{2}$ solicitors are usually barred from attending the meeting of experts. However, it does happen, and in the Expert Witness Institute's survey, opinion was about equally divided on their value. My own experience is limited to one four-way telephone conference among two experts and their respective instructing solicitors; this seemed a successful arrangement. The presence of solicitors would ensure that all issues were addressed and should prevent resilement. Because of the expense and practical difficulties, it might be reserved for complex cases.

Two-thirds of the conferences were conducted by telephone, but most responders believed that conferences in person are more likely to be productive, successful, and conclusive. That is my opinion too. Conferences in person not only allow freer discussion but also permit joint review of medical records and in particular radiographs and the preparation of the joint statement by one expert in the presence of and with the approval of the other or others. In telephone conferences documents do not come so easily to hand. Importantly, one or other expert will generally dictate a draft joint statement at the conclusion of the conference, sending it to the other or others for approval. This commonly leads to transmission of amendments and modifications back and forth. In such cases, the expert who prepares the statement has the upper hand. The other may ultimately concede and sign a statement which is not entirely satisfactory to him or her, or abandon the project and refer the matter back to the instructing solicitor.

Relative cost and practicality are factors in deciding whether or not conferences are to be held by telephone or in person, and the experts should seek instruction here.

\section{CONCLUSIONS}

1 Pretrial conferences of experts have proved their worth

2 The courts could be more selective when ordering them, and more realistic when laying down timescales

3 They could be rendered more cost-effective and successful by more careful preparation, both by the insurers/solicitors and by the experts

4 An agenda is helpful and desirable, but its preparation is hindered by legal hanky-panky

5 The presence of solicitors at conferences is permissible and can be helpful, but is seldom necessary

6 Conferences in person are more productive, and the joint statements produced following them more definitive, than telephone conferences

7 Consideration should be given to a combined audit of conferencing by the medical and legal professions.

\section{REFERENCES}

1 Butler-Sloss E, Hall A. Expert witnesses, courts and the law. J R Soc Med 2002;95:431-4

2 Stevens J. Legal View: UK Casebook 19. London: Medical Protection Society, 2003

3 Macnicol MF. The impact of the Woolf Reforms. British Orthopaedic News 2000 (Summer) 24-5

4 Expert Witness Inst Newsl 2001 (autumn/winter) (suppl) 